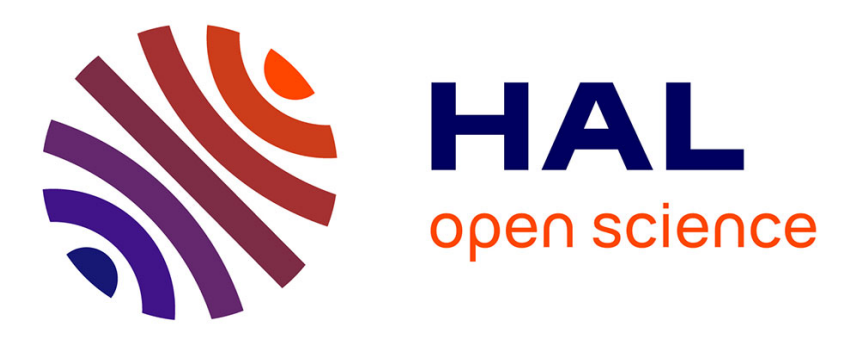

\title{
Active Acoustic Signature Extraction by Machine Learning Data Analysis for Underwater Fish Counters
}

Gabriel Vasile, Alexandre Girard, Guy d'Urso, Eric de Oliveira, Franck Hieramente, Olivier Philippe

\section{- To cite this version:}

Gabriel Vasile, Alexandre Girard, Guy d'Urso, Eric de Oliveira, Franck Hieramente, et al.. Active Acoustic Signature Extraction by Machine Learning Data Analysis for Underwater Fish Counters. OCEANS 2020 - OCEANS '20 MTS/IEEE, Oct 2020, Gulf Coast, United States. 10.1109/IEEECONF38699.2020.9389105 . hal-03004372

\section{HAL Id: hal-03004372 \\ https://hal.science/hal-03004372}

Submitted on 13 Nov 2020

HAL is a multi-disciplinary open access archive for the deposit and dissemination of scientific research documents, whether they are published or not. The documents may come from teaching and research institutions in France or abroad, or from public or private research centers.
L'archive ouverte pluridisciplinaire HAL, est destinée au dépôt et à la diffusion de documents scientifiques de niveau recherche, publiés ou non, émanant des établissements d'enseignement et de recherche français ou étrangers, des laboratoires publics ou privés. 


\title{
Active Acoustic Signature Extraction by Machine Learning Data Analysis for Underwater Fish Counters
}

\author{
Gabriel Vasile \\ Grenoble-Image-sPeech-Signal-Automatics Lab \\ CNRS / Université Grenoble Alpes \\ Grenoble Cedex, France \\ gabriel.vasile@grenoble-inp.fr \\ Guy d'Urso \\ Laboratoire National d'Hydraulique et Environnement \\ EDF R\&D LNHE \\ Chatou, France \\ guy.durso@edf.fr
}

\author{
Alexandre Girard \\ Laboratoire National d'Hydraulique et Environnement \\ EDF R\&D LNHE \\ Chatou, France \\ alexandre.girard@edf.fr \\ Eric De Oliveira \\ Laboratoire National d'Hydraulique et Environnement \\ $E D F R \& D L N H E$ \\ Chatou, France \\ eric.de-oliveira@edf.fr
}

\author{
Franck Hieramente and Olivier Philippe \\ OSEAN S.A.S. \\ ZAE la Bayette \\ Le Pradet, France \\ franck.hieramente@osean.fr, olivier.philippe@osean.fr
}

\begin{abstract}
This paper illustrates our recent advances in terms of supervised classification of different acoustics signatures employed for fish monitoring by the ACOUEAU active ultrasound system. The obtained results are analyzed, both qualitatively and quantitatively, by taking into consideration five target types.

Index Terms-underwater acoustics, fish classification, machine learning
\end{abstract}

\section{INTRODUCTION}

Fish counting facilities play an important role in river system biodiversity monitoring. The ability of current hydropower plants to allow unobstructed passage for migrating fish species is a common requirement. The European Commission has published a set of recommendations for the use of dedicated passage channels (or fish passes) to by-pass the fish migration paths and to allow the up/down stream migration of fish species [1].

Monitoring fish passages is currently preformed using different technologies, like camera filming, infrared systems, passive sonars, active acoustic tagging or RFID tagging [2] [5]. Spampinato et al. introduced in [6] an underwater imaging system for detecting fishes in Ken-Ding, Taiwan. The proposed imaging systems has three subcomponents: texture analysis, fish detection and fish tracking. The main inconvenient of such a system is the fact that it can operate during the day or with artificial illumination, only.

A second method for fish counting is based on resistive measurements [7]. Using two electrodes, this monitoring system is measuring the conductivity fluctuations (slight decrease in amplitude) when a fish is passing through. Such techniques are well suited for calm underwater environments such as the fish elevators where no considerable turbulent follow is present.

An et al. introduced ultrasound for fish monitoring [8]: by using an ultrasound emitter, the acoustic signal scattered by the fish is analyzed using three underwater cameras. In this context, an active ultrasound fish monitoring system can efficiently contribute to detect, quantify and identify in the water column the fish species continuously.

In this paper, we present our recent advances in the field of active ultrasound fish detection capabilities developed in the framework of the FEDER ACOUEAU ${ }^{1}$ European Project funded through the PACA county, France. The main goal of this project is to develop multiple acoustic barriers for reliable fish counting in downstream fish passes. In [9], [10], we introduced an Internet of Things (IoT) cost effective 500 $\mathrm{kHz}$ acoustic system for counting fishes in passage channels, which operates on the principle of multi-static acoustic antenna [11]-[13]. It was composed of several acoustic barriers: each fish passage will obstruct the acoustic propagation channel between the emitter and the receiver, which makes possible fish monitoring. The acoustic barrier can act as an independent conventional immersed wideband ultrasound system in bistatic configuration.

Because the passage channel is a noisy and a relatively fast changing environment, our motivation for designing the

\footnotetext{
${ }^{1}$ http://www.osean.fr/fr/feder-acou-eau.php
} 
proposed IoT system is to increase the quality of signals and to simplify the computational load of the processing algorithms for the detection of events. The proper use of this technique relies on two main hypotheses.

The first one concerns the Signal-To-Noise (SNR) ratio, namely any fish passage will decrease the received SNR by a significant amount. This has been insured by employing adaptive acoustic channel equalization [14] coupled with the use of wide-band transmission waveforms [15].

The second hypothesis relies on the ability to recognize the external perturbation on the acoustic path [10], [16].

This paper is structured as follows. Section II presents a new method to isolate the acoustic background from the passages of interest, while Section III introduces the proposed fish recognition algorithm. Section IV illustrates both qualitative and quantitative performance assessment. Section V concludes the paper.

\section{AcOustic BACKGROUND STATISTICAL DETECTION}

Before further processing, one important step consists in distinguishing between the unperturbed reference signal (background) and the received acoustic signal affected by any fish passage. By considering the fish passages as sparse events, we propose to take advantage of the asymptotic Probability Density Function (PDF) of the Sum-of-Squares (SS) estimate:

$$
X_{S S}=\sum_{i=1}^{L}\left|X_{i}\right|^{2},
$$

where $X$ is the complex spectrum of the signal contained in each burst and $L$ is the burst number of samples.

Under the hypothesis that $X$ follows the complex circular normal distribution, the $X_{S S}$ will asymptotically converge to a Gamma distribution with parameters $\bar{X}_{S S}$ (mean) and $L$ (degrees of freedom). Given the fact that $L$ is large, we consider that $\bar{X}_{S S}$ is a deterministic quantity and thus it is approximated by its median value $\widehat{X}_{S S}$.

For a background signal, the PDF of the ratio $\frac{X_{S S}}{\widehat{X}_{S S}}$ is:

$$
p_{\frac{X_{S S}}{\widetilde{X_{S S}}}}(x)=\frac{L^{L} x^{L-1}}{\Gamma(L)} e^{-L x} .
$$

The length of the $95 \%$ confidence interval (centered around 1) is expressed in terms of the coefficient of variation $C V=\frac{1}{\sqrt{L}}$ as $2 C V$ [17], [18].

In the proposed model, the occurring fish passages are considered as outliers of this PDF: if the ratio $\frac{X_{S S}}{\widehat{X}_{S S}}$ exceeds $2 C V$, the received acoustic signal is considered as a fish passage.

\section{FISH RECOGNITION BY MACHINE LEARNING}

Several experimental observations [10], [16], have led us to the machine learning algorithm proposed in this paper for fish recognition. It is composed of two stages:

- the training step - a training database is used to extract the information required for the acoustic signature characterization;
- the recognition step - using the previously derived target descriptors, the final decision criterion is computed.

Before applying the machine learning stage, a preprocessing step is required in order to cancel the propagation effects of the bistatic system and its environment, namely background deconvolution. The background is thus removed using the Tikhonov deconvolution [19]:

$$
x^{n o r m}=\mathbf{i F F T}\left[\left(X \otimes B^{*}\right)\left(B \otimes B^{*}+R\right)^{-1}\right],
$$

where $X$ and $B$ are the complex spectra of the input and background signals after applying Hanning weighting. The background acoustic signature $B$ is obtained in the spectral domain by the trimmed mean estimator and the regularization constant $R$ is set according to $5 \%$ of the dynamic range of the input signal.

Finally, in order to remove the main lobe of $x^{\text {norm }}$, the Hanning weighting is applied before shifting.

\section{A. Training}

This step requires a training database $[X]^{\text {train }}$ arranged as a 3D tensor of size $N \times n \times m$, where $N$ is the number of samples and $n$ is the number of signals available for each of the $m$ targets. It can be summarized as:

1) compute the Hilbert transform of each signal $[X]_{\text {Hilbert }}^{\text {train }}$ along the dimension $N$;

2) evaluate the Fast Fourier Transform (FFT) $[X]_{F F T}^{\text {train }}$ along the same dimension;

3) take the mean over the dimension $n$ to derive $[X]_{\text {mean }}^{\text {train }}$;

4) perform the inverse FFT (iFFT) along $N$ to derive $[X]_{\text {reference }}^{\text {train }}$.

The derived matrix $[X]_{\text {reference }}^{\text {train }}$ of size $N \times m$ is completely characterizing each of the $m$ targets of interest.

\section{B. Recognition}

Using the previously derived reference functions, each recorded signal under test $x^{\text {test }}$, of size $N$, is processed according to the following steps:

1) compute the Hilbert transform $x_{\text {Hilbert }}^{\text {test }}$;

2) for each $i \in\{1 . . m\}$ target types, compute the corresponding match filter $x_{M F_{i}}^{t e s t}$

3) the received signal is assign to the dominant target type $k$ according to the criterion

$$
k=\operatorname{argmax}_{i \in\{1 . . m\}}\left\{M A X_{N}\left|x_{M F_{i}}^{t e s t}\right|\right\} .
$$

The final classification label is set according to the criterion from Eq. 4, which is maximized when the acoustic signature is identical to the class reference function.

\section{RESUlTS AND Discussion}

In order to validate the proposed algorithm, an experimental campaign has been realized in controlled environment (EDF Chatou Lab) in February 2020. During this experimentation, the nominal bandwidth has been selected between $300 \mathrm{KHz}$ and $600 \mathrm{KHz}$, at $0.6 \mathrm{~m} / \mathrm{s}$ flow, with $m=5$ representative target types: trout (C50m6), small leaves (C50m6PF), large 

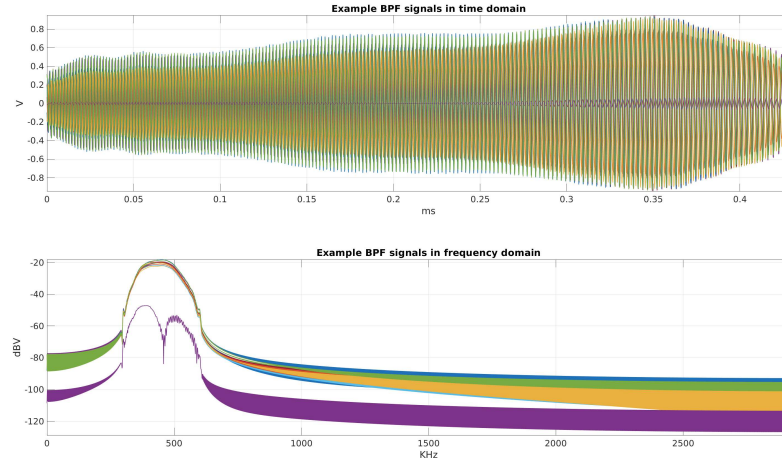

Fig. 1. Example of one signals after band pass filtering: time domain (up) and spectral domain (down).

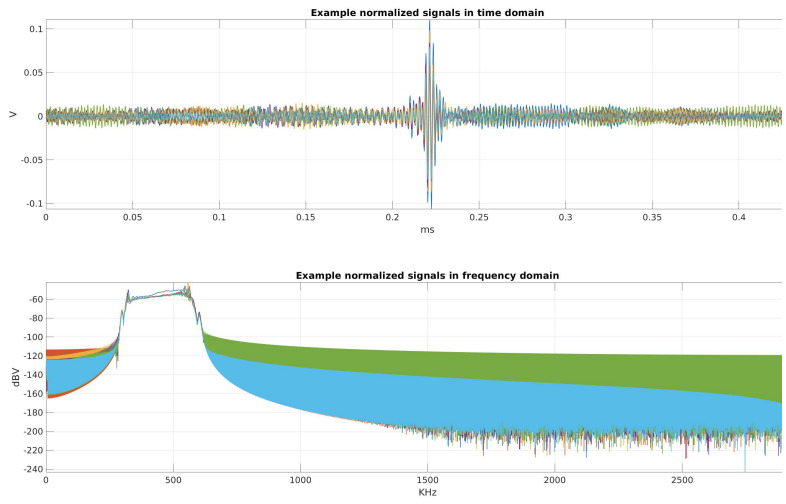

Fig. 2. Example of one normalized signals after background deconvoluuvi. time domain (up) and spectral domain (down).

leaves (C50m6GF), small wood branches (C50m6PFG) and large wood branches (C50m6GFG).

Fig. 1 illustrates an example of received signals after band pass filtering, spanning one buffer, while Fig. 2 shows the same signals after background deconvolution. One can notice that only 6 channels contain useful information. All other channels were not submerged due to the reduced section of the testing facility.

The results obtained by the proposed background statistical detector are shown in Figs. 3 and 4. They correspond to the trout passages within the selected six acoustic barriers. While the results obtained using the last five barriers $(\mathrm{CH} 2$ to CH6) are consistent, the first acoustic barrier $(\mathrm{CH} 1)$ is exhibiting a considerably lower performance. This is due to the fact that $\mathrm{CH} 1$ is placed at the top of the section and thus the occurrence of waves is violating the passage sparsenesses condition detailed in Sect. II.

In order to validate the proposed acoustic target classification algorithm, the histograms of the criterion from Eq. 4 for all five classes are presented in Fig. 5. The dataset corresponds to the trout passages, only. It can be seen that the proposed criterion achieves the required separation between the true and

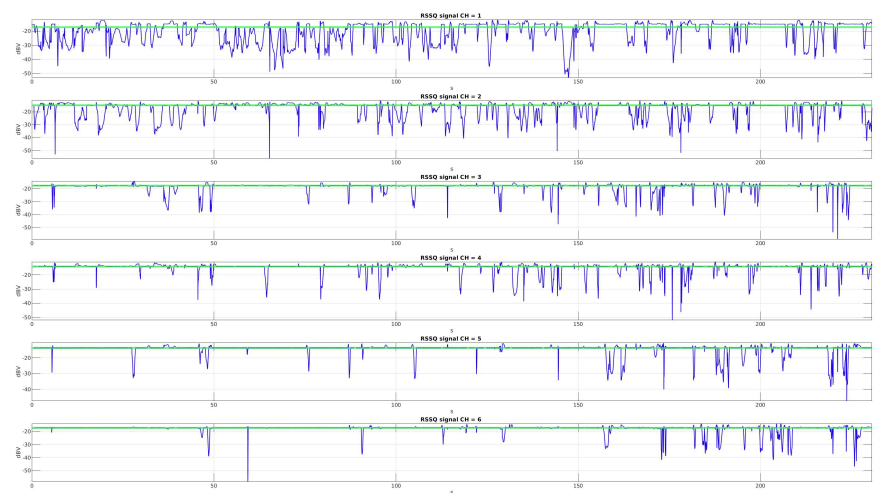

Fig. 3. Active ultrasound fish / background selection: SS time series, 6 channels.

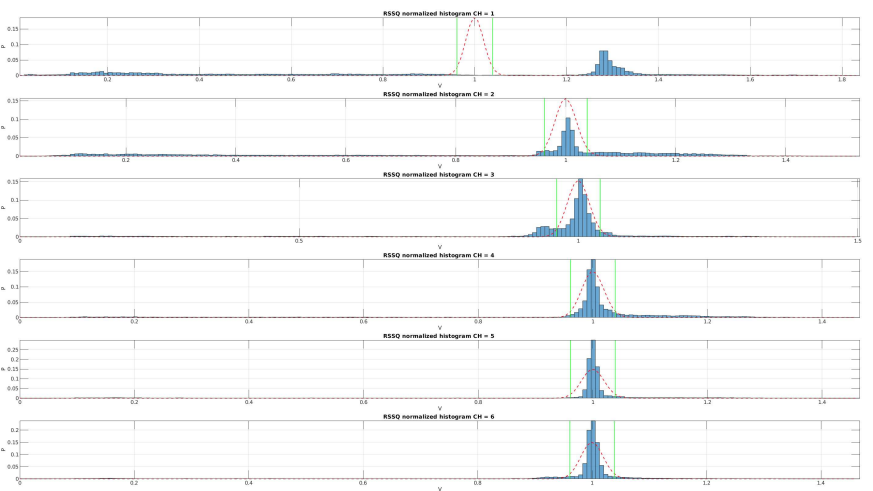

Fig. 4. Active ultrasound fish / background selection: histogram of the SS time series with the corresponding background confidence interval.

the false classes.

Quantitative performance analysis is shown in Table I for the trout passages, also. More than $99 \%$ of the recorded signals were correctly classified.

"Temperature/K".

\section{CONCLUSION}

This paper proposed a method to classify acoustic signatures provided by different acoustic barriers in order to be able to perform fish counting in a time varying shallow water environment. It was shown that the obtained results present a high degree of accuracy with respect to the ground truth. Future studies include the inclusion of time adaptive estimation for continuous unsupervised monitoring.

\section{ACKNOWLEDGMENT}

This work has been developed in the framework of the ACOUEAU project, supported by the European Union Regional Development Fund. The authors would like to thank to Steeve Zozor, Amaury Nègre and Pascal Bellemain, form the GIPSA-lab, to Gery Hachet, from the EDF R\&D and to 


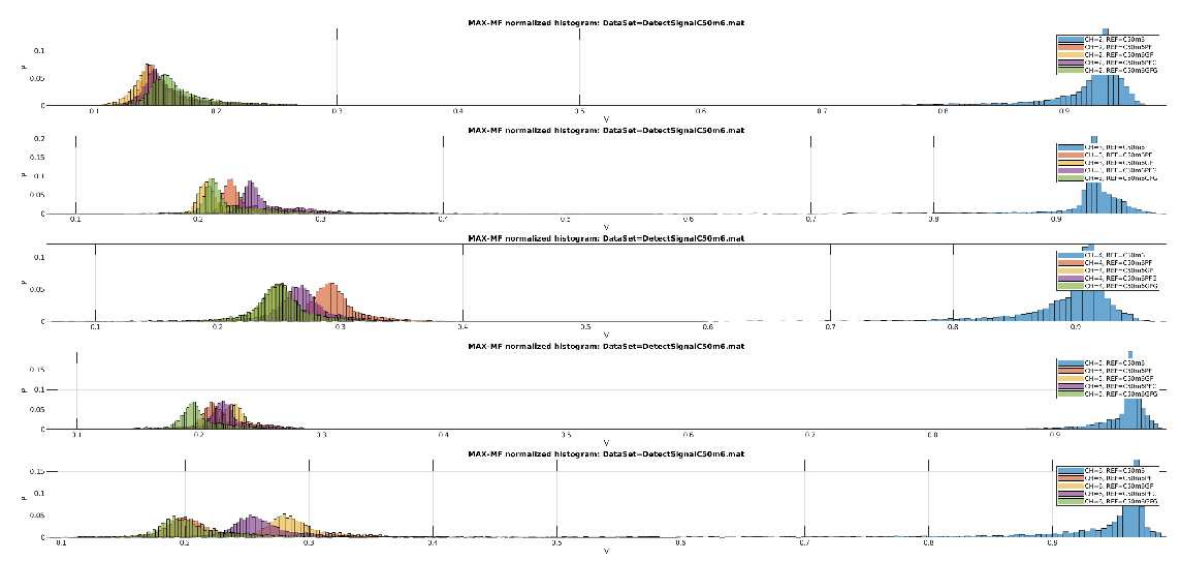

Fig. 5. Active ultrasound fish recognition, separability between classes: histograms of the the criterion from Eq. 4.

TABLE I

QUANTITATIVE PERFORMANCE ASSESSMENT (PERCENTAGE) FOR THE TARGET CLASSIFICATION ALGORITHM FOR THE TROUT PASSAGES: C50M6 IS THE TRUE CLASS, WHILE C50M6PF, C50M6GF, C50M6PFG AND C50M6GFG ARE THE FALSE CLASSES.

\begin{tabular}{||c||c|c|c|c|c||}
\hline \hline & C50m6 & C50m6PF & C50m6GF & C50m6PFG & C50m6GFG \\
\hline \hline CH2 & 99.50 & 0.11 & 0.17 & 0.09 & 0.13 \\
\hline CH3 & 99.98 & 0 & 0.02 & 0 & 0 \\
\hline CH4 & 99.63 & 0 & 0.37 & 0 & 0 \\
\hline CH5 & 100.0 & 0 & 0 & 0 & 0 \\
\hline CH6 & 99.81 & 0.15 & 0.02 & 0 & 0.02 \\
\hline \hline
\end{tabular}

Fabrice Huitorel from the OSEAN for their precious support in hardware and software development.

\section{REFERENCES}

[1] E. European Small Hydropower Association, "Strategic study for development of small hydropower in the European Union," Tech. Rep. Renewable Energy House, 2008.

[2] M. Cuchet, M. Muhlbauer, C. Ratschan, A. Hartlieb, and B. Brinkmeier, "Behavioural experiments on the design of downstream fish passage facilities for potamodromous species," in Proceedings of the IAHR World Congress - Balance and Uncertainty, Brisbane, Australia, 2011, pp. 2792-2798.

[3] P. Pompeu and C. Martinez, "Efficiency and selectivity of a trap and truck fish passage system in Brazil," Neotropical Ichthyology, vol. 5, no. 2, pp. 169-176, 2007.

[4] M. Larnier, "Pool fishways, pre-barrages and natural bypass channels," Bulletin Français de la Pêche et de la Pisciculture, vol. 364, pp. 54-82, 2002.

[5] M. Larnier and F. Travade, "Downstream migration: problems and facilities," Bulletin Français de la Pêche et de la Pisciculture, vol. 364, pp. 181-207, 2002.

[6] C. Spampinato, Y. H. Chen-Burger, G. Nadarajan, and R. Fisher, "Detecting, tracking and counting fish in low quality unconstrained underwater videos," in Proceedings of the 3rd Int. Conf. on Computer Vision Theory and Applications (VISAPP), vol. 2, 2008, pp. 514-519.

[7] I. P. Smith, A. D. F. Johnstone, and D. A. Dunkley, "Development of a "weir-less" electrode array for a resistivity fish counter: results of field trials in 1993," Scottish Fisheries Research Services, Tech. Rep. 04/94, 1994.

[8] H. P. An, B. Lundgren, B. Stage, and J. A. Jensen, "Ultrasound backscatter from free-swimming fish at $1 \mathrm{MHz}$ for fish identification," in Proceedings of the IEEE International Ultrasonics Symposium (IUS), 2012, pp. 1477-1480.

[9] G. Vasile, T. Petrut, G. d'Urso, and E. de Oliveira, "Iot acoustic antenna development for fish biomass long-term monitoring," in Proceedings of the MTS/IEEE North American OCEANS conference, Charleston, South Carolina, USA, 2018, pp. 1-4.
[10] G. Vasile, P. Bellemain, G. d'Urso, and E. de Oliveira, "Real-time wideband acoustic signal processing for fish counting," in Proceedings of the MTS/IEEE North American OCEANS conference, Charleston, South Carolina, USA, 2018, pp. 1-4.

[11] G. Vasile, G. d'Urso, E. de Oliveira, J. Guillet, and E. Lungu, "Reference selection for an active ultrasound wild salmon monitoring system," in Proceedings of the MTS/IEEE North American OCEANS conference, Washington, DC, USA, 2015, pp. 1-4.

[12] G. Vasile, G. d'Urso, R. Charlatchka, and E. Lungu, "Calibration of an active ultrasound bedload monitoring system for underwater environments," in Proceedings of the MTS/IEEE North American OCEANS conference, Washington, DC, USA, 2015, pp. 1-4.

[13] G. Vasile, G. d'Urso, A. Goarant, E. de Oliveira, and E. Lungu, "Potential of active ultrasound monitoring systems for jellyfish detection," in Proceedings of the MTS/IEEE North American OCEANS conference, Monterey, CA, USA, 2016, pp. 1-4.

[14] G. Vasile, G. d'Urso, E. de Oliveira, and E. Lungu, "Online software nonlinearity correction for wideband active ultrasound monitoring systems," in Proceedings of the MTS/IEEE North American OCEANS conference, Anchorage, Alaska, USA, 2017, pp. 1-4.

[15] _ - "Transmission waveform analysis for active ultrasound fish monitoring systems," in Proceedings of the MTS/IEEE North American OCEANS conference, Anchorage, Alaska, USA, 2017, pp. 1-4.

[16] G. Vasile, A. Girard, G. d'Urso, E. de Oliveira, F. Hieramente, and O. Philippe, "Experimental acoustic data analysis for fish detection using an active ultrasound system," in Proceedings of the MTS/IEEE North American OCEANS conference, Seattle, Washington, USA, 2019, pp. 14.

[17] G. Vasile, E. Trouvè, M. Ciuc, P. Bolon, and V. Buzuloiu, "Intensitydriven-adaptive-neighborhood technique for POLSAR parameters estimation," in Proceedings of the IEEE Geoscience And Remote Sensing Symposium, Seoul, Korea, vol. 8, 2005, pp. 5509-5512.

[18] N. Besic, G. Vasile, J. Dedieu, J. Chanussot, and S. Stankovic, "Stochastic approach in wet snow detection using multitemporal SAR data)," IEEE Geoscience and Remote Sensing Letters, vol. 12, no. 2, pp. 244$248,2015$.

[19] A. Tikhonov and V. Arsenin, Solution of ill-posed problems. Wiston/Wiley, Washington, 1977. 